\title{
Conselho Municipal de Saúde sob a ótica de seus conselheiros: estudo realizado em uma capital brasileira
}

\author{
Municipal Council of Health under the perspective of its councillors: a study in a \\ brazilian capital
}

\section{Conseil Municipal de la Santé dans le cadre du point de vue de ses conseillers: une étude dans un capitale brésilienne}
Consejo Municipal de Salud bajo la perspectiva de sus consejeros: un estudio realizado en un capital de Brasil

\author{
Bruno de Jesus Lopes* \\ (bruno.jesus@ufv.br) \\ Edson Arlindo Silva* \\ (edsonsilva@ufv.br) \\ Simone Martins* \\ (Simone.m@ufv.br)
}

Recebido em 21/09/2015; revisado e aprovado em 10/10/2015; aceito em 16/11/2015

DOI: http:/ / dx.doi.org/10.20435/1984042X2016201

\begin{abstract}
Resumo: Os conselhos de saúde no Brasil são instituições híbridas que permitem a inserção da sociedade nas discussões políticas. Assim, neste artigo, buscou-se compreender o funcionamento e as contribuições do Conselho Municipal de Saúde de Belo Horizonte para a inserção da sociedade nos processos políticos. Os dados foram coletados por meio de entrevista semiestruturada e apresentados a partir de uma análise descritiva e interpretativa. Como resultados, foram observadas limitações no conselho que prejudicam seu funcionamento.

Palavras-chave: democracia deliberativa; Conselhos de Políticas Públicas; participação.

Abstract: Health councils in Brazil are hybrid institutions that allow the inclusion of society in political discussions. So this article sought to understand the working and the contributions of the Belo Horizonte Municipal Health Council for the inclusion of society in political processes. The data has been collected through semi structured interviews and submitted from a descriptive and interpretative analysis. The result, demonstrated there are limitations on the council that impair its functioning.
\end{abstract}

Key words: deliberative democracy; Public Policy Councils; participation.

Résumé: Conseils de santé au Brésil sont des institutions hybrides qui permettent l'inclusion de la société dans les discussions politiques. Donc, dans cet article, nous avons essayé de comprendre le fonctionnement et les contributions du Conseil municipal de la santé de Belo Horizonte pour l'inclusion de la société dans les processus politiques. Les données ont été recueillies travers des interviews semi-structurées et soumises à partir d'une analyse descriptive et interprétative. En conséquence, il ya des limites sur le conseil qui altère son fonctionnement.

Mots-clés: democratie délibérative; Conseils de Politiques Publiques; participation.

Resumen: Los consejos de La salud em Brasil son instituiciones híbridas que permiten la inserción de la sociedad en las debates políticos. Por lo tanto, en este artículo trato de compreenderse El funcionamiento y las contribuiciones del Consejo Municipal de la Salud de Belo Horizonte para la inserción de la sociedad en lós procesos políticos. Los datos fueron obtenidos por la entrevista semiestructurada y presentados partir de un análisis descriptivo e interpretativo. Como resultado, hay limitaciones en el consejo que deterioran el funcionamiento.

Palabras clave: democracia deliberativa, Consejos de Políticas Públicas, participación.

\section{INTRODUÇÃO}

No final do período militar, o Brasil encontrava-se em um cenário de forte propensão participativa e em busca de um modelo democrático que estabelecesse diretrizes descentralizadoras com aporte no compartilhamento da gestão política com a sociedade.
Em resposta, a Constituição Federal de 1988 garantiu a participação da sociedade nas discussões políticas, principalmente nas áreas da saúde e da assistência social. A institucionalização desses espaços ocorreu nos anos seguintes, contando com normas legais de criação e de funcionamento dos conselhos de políticas públicas.

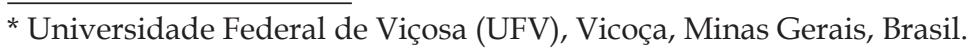


Os Conselhos de Saúde, objeto deste estudo, representam uma conquista da sociedade frente ao processo decisório para as políticas desse setor, uma vez que "são espaços deliberativos da engenharia político-institucional do Sistema Único de Saúde do Brasil, constituindo uma inovação crucial para a democratização das decisões setoriais" (LABRA, 2005, p. 353). Essa forma institucionalizada de participação cívica se aproxima de um modelo democrático que tem como um dos principais precursores Habermas (1995), denominado de "Democracia Deliberativa". Nesse modelo, buscam-se formas de interação entre Estado e sociedade com base na comunicação racional.

Nos Conselhos de Saúde, dentre as normas que definem os procedimentos desse espaço, destaca-se a Lei 8.142 de 1990, que dispõe sobre a criação do Conselho como forma de gestão partilhada da saúde, e a Resolução 453 de 2012, que substitui a 333 de 2003 e define-lhe a organização, funcionamento e competências.

Ao Conselho Municipal de Saúde é atribuído o poder de decidir conjuntamente com o governo, tendo autonomia necessária para exercer o controle sobre a gestão do SUS e atuar, de maneira propositiva, em todas as instâncias federativas. Desse modo, objetivou-se com este artigo compreender, a partir da percepção dos conselheiros, o funcionamento e as contribuições do Conselho Municipal de Saúde de Belo Horizonte para a inserção da sociedade nos processos políticos e, consequentemente, para o compartilhamento da gestão da política de saúde. Buscou-se também descobrir se os conselheiros reconhecem o cumprimento do papel institucional do Conselho nesse novo modelo democrático.

Para alcançar os objetivos almejados, foi realizado um estudo de caso do Conselho Municipal de Saúde de Belo Horizonte, um dos mais antigos em atividade no Brasil, possuindo uma rede de participação que envolve todo o município. Para tanto, o artigo contempla uma breve discussão sobre os fundamentos da Democracia Deliberativa, participação social e apresenta uma perspectiva quanto aos conselhos de políticas públicas na área da saúde. Para apresentação dos resultados, numa abordagem qualitativa, foi realizada uma análise descritiva interpretativa dos de- poimentos dos entrevistados. Por fim, foram expostas as considerações finais, contemplando os principais achados da pesquisa e algumas sugestões para outros estudos.

\subsection{Fundamentos teóricos da Democracia Deliberativa}

Os Conselhos de Políticas Públicas são instituições participativas cujas bases estão fortemente associadas aos conceitos da democracia deliberativa. Jürgen Habermas (1995), um dos precursores dessa teoria, ao construir uma crítica aos modelos liberalista e republicano, propõe uma terceira via democrática em direção a um modelo deliberacionista com suporte na participação dos diversos setores da sociedade e do Estado, por meio do discurso e da comunicação racional.

Apesar de sua reconhecida importância, a teoria habermasiana recebe muitas críticas por não se preocupar em possibilitar a compreensão sobre o lugar onde a deliberação ocorre e por não explicar como o poder comunicativo influenciaria as decisões políticas. Dessa forma, outros autores buscam suprir essas lacunas teorizando sobre espaços legitimados para o exercício deliberativo, como os Conselhos de Políticas Públicas, através dos quais todos que possuem interesse podem e têm o direito de participar das decisões acerca do bem comum.

Por isso, tornam-se relevantes as palavras de Cohen (2009, p. 85), "por democracia deliberativa entendo, aproximadamente, uma associação cujas relações são governadas pela deliberação pública de seus membros" e as de Bohman (2009), para quem o ideal no processo deliberativo é a participação de todos os cidadãos na tomada de decisão; sem deixar de reconhecer, a inexibilidade de ocorrência desse fato na sociedade atual, caracterizada pela complexidade, tanto em sua extensão, quanto na pluralidade.

De acordo com Ugarte (2004), um dos elementos da democracia deliberativa é justamente a ideia de que todos devem participar de forma coletiva na tomada de decisão sobre as políticas que lhe são destinadas, mas, devido à impossibilidade de espaços nessas proporções, essas deliberações devem acontecer entre representantes escolhidos pela sociedade. 
A título de exemplo da aplicação de representatividade de Bohman (2009), os Conselhos Municipais de Saúde têm seus representantes eleitos pelos participantes das instituições que com eles se envolvem, como é o caso, por exemplo, das unidades de atendimento, sindicatos, associações e grupos de apoio aos doentes. Benhabib (2009) destaca que o funcionamento dessa instituição na democracia deliberativa para que esta seja legitima, necessita que todos aqueles envolvidos no processo deliberativo sejam tratados como iguais, sem preconceitos relacionados a níveis de escolaridade, faixa etária, gênero ou outras características quaisquer.

Seguindo a linha de Habermas (1995), Cohen (2009) descreve que a legitimidade da democracia deliberativa está na troca de razões entre os indivíduos por intermédio da comunicação igualitária e pluralista. Para que essa legitimidade seja alcançada, Cohen descreve o procedimento ideal para uma democracia deliberativa e argumenta que existem três aspectos sobre este, "[...] decidir sobre uma agenda, propor soluções alternativas para os problemas dessa agenda, sustentar essas soluções com razões e concluir apresentando uma alternativa" (COHEN, 2009, p. 92).

Assim, partindo dos pressupostos de que a democracia deliberativa é o livre discurso entre os cidadãos, percebe-se, nesse novo método decisório, a força da população na agenda política, justificando, assim, a necessidade de buscar conhecer mais sobre a participação cívica brasileira para compreender o espaço deliberativo que é o Conselho Municipal de Saúde.

\subsection{Participação Cívica no Brasil}

De acordo com Avritzer (2010), o Brasil, até a década de 1980, podia ser considerado um país com uma baixa propensão participativa, devido às características culturais e administrativas do país, fortemente ligadas à verticalização das decisões e ao clientelismo.

Pode-se considerar, em parte, que as marcas, desde o período patrimonialista, caracterizado principalmente pela figura do coronel, fomentaram as atitudes políticas e as formas de gerenciamento da administração pública. Resumidamente, aqueles com maiores condições econômicas se sobressaíam por meio de favores àqueles que não tinham.
Após o patrimonialismo, adotou-se no Brasil o modelo de administração burocrático, a partir do qual, Bresser Pereira (2005) enumera um conjunto de princípios que dão forma e visibilidade ao modelo, indo além da caracterização deste, justificando o baixo envolvimento da população com a coisa pública e a pouca propensão à participação, em que se destacam: formalização das funções e atividades administrativas; unidade de comando fundamentada na organização hierárquica das instituições; centralização de poder via processo decisório.

Vale destacar também o modelo Gerencialista que focou seus objetivos em duas frentes: de um lado, a incorporação por parte dos gestores públicos de técnicas e ferramentas gerenciais semelhantes ao do meio privado; do outro, a propagação de ideias de Estado Mínimo e enxugamento da "máquina pública". Ambas as frentes de perspectivas gerencialistas procuravam reestruturar o Estado-Nação nos moldes da administração privada e das orientações advindas do processo de globalização (PAULA, 2005; BRESSER PEREIRA, 2010; SPINK, 1998).

Todos esses modelos, de acordo com as características descritas, deram pouco espaço para o envolvimento da população nas discussão das políticas públicas relacionadas ao bem comum. Ainda assim, algumas situações, como as manifestações dos trabalhadores por auxílios previdenciários e movimentos sanitaristas por melhores condições na saúde pública, contribuíram para o desenvolvimento de uma política com orientação participativa.

Essas mudanças, segundo Avritzer e Pereira (2005), são os resultados de um longo processo de reorganização da sociedade civil, das suas formas de relação com o Estado e de um longo processo de transformações institucionais, jurídicas e administrativas, especialmente a nível local.

\subsection{Conselho Municipal de Saúde}

Três meses após a institucionalização do Sistema Único de Saúde com a lei 8.080 de 1990, foi sancionada a lei 8.142 dispondo sobre a participação da sociedade na gestão do SUS a partir dos Conselhos de Saúde.

Esta lei, ao definir o Conselho, descreve sua composição tripartite (com representante 
da sociedade, trabalhadores, prestadores de serviço e Estado) assim como suas competências, fazendo desse espaço um membro presente na agenda de políticas públicas de saúde, na formulação e controle de políticas e na fiscalização das ações destas. As resoluções que foram escritas na sequência, tendo a mais atual a 453 de 2012, confirmaram o papel do Conselho além de definir suas principais diretrizes.

Um ponto a ser destacado desse espaço é a função deliberativa do Conselho. O CMS participa da gestão da saúde em diferentes frentes, na fiscalização das unidades de atendimento, na elaboração de políticas e no controle orçamentário e econômico, a partir de resoluções, recomendações e moções, sendo as decisões acerca desses assuntos realizadas de forma conjunta entre a sociedade, gestores, prestadores e trabalhadores na área da saúde em plenária aberta.

Além da participação cívica em moldes deliberativos, esse espaço é carregado de poder e autonomia em suas atribuições. Ainda assim, as normas do conselho estabelecem que o gestor da saúde deve homologar as decisões deliberadas mesmo após aprovação do Conselho e, quando não for feito, deve, por obrigação, prestar esclarecimentos.

Para identificar a percepção dos conselheiros em relação ao Conselho, sobre o papel e funcionamento deste, a metodologia utilizada neste estudo será apresentada na seção seguinte.

\section{ASPECTOS METODOLÓGICOS}

O objetivo desta seção é descrever as principais ferramentas metodológicas utilizadas para desenvolvimento deste estudo.

\subsection{Caracterização do Conselho Municipal de Saúde de Belo Horizonte}

O Conselho Municipal de Saúde de Belo Horizonte (CMS/BH) pode ser considerado como um dos principais e mais antigos Conselhos no Brasil. Sua história vai além da institucionalização da Lei 8.142, existindo, antes desta, com mobilizações da sociedade em relação à saúde pública.

Em termos normativos, o CMS/BH foi regulamentado pela Lei Municipal 5.903 de
1991, alterada pela 7.536 de 1998. Pelo seu regimento interno, o Conselho é composto por 18 representantes da sociedade civil, 09 representantes do segmento gestor e de prestadores de serviços de saúde e 09 de representantes dos trabalhadores em saúde.

O Conselho conta ainda com Câmaras Técnicas. De acordo com o Regimento Interno do Conselho, a finalidade destas é otimizar e agilizar o funcionamento do Conselho referente a cada tema e propor soluções que serão apresentadas ao plenário.

\subsection{Ferramentas Metodológicas}

Este estudo se caracteriza como qualitativo. Nesse modelo, a pesquisa tem por objetivo traduzir e expressar o sentido dos fenômenos do mundo social; trata-se de reduzir a distância entre "pesquisado" e "pesquisador", entre "teoria" e "dados", entre "contexto" e "ação" (MAANEN apud NEVES, 1996).

Os dados coletados são de origem primária, tendo como base entrevistas semiestruturadas realizadas com os membros titulares do CMS/BH. De acordo com Alencar (2000), entende-se por entrevista semiestruturada aquela que parte de certos questionamentos básicos, apoiados em teorias ou objetivos do estudo e que oferecem amplo espaço de interrogativas, resultante do diálogo com os informantes.

No total, foram entrevistados 15 conselheiros, sendo nove representantes dos usuários, três representantes dos gestores/prestadores e três membros dos trabalhadores.

O roteiro para execução das entrevistas teve como foco o perfil dos conselheiros, procurando conhecer suas faixas etárias, escolaridade e opções partidárias; além disso, objetivou-se conhecer o entendimento dos entrevistados sobre o Conselho, questões relacionadas acerca de seu funcionamento, assim como os pontos positivos e negativos desse espaço democrático.

Por fim, foi feita uma Análise Descritiva/ Interpretativa das entrevistas. De acordo com Godoy (2006), nesse método as informações coletadas serão estudadas como um todo, sem categorização, mas com interpretação do pesquisador, buscando entrar padrões que possibilitem confirmar ou opor-se a suposições teóricas. 


\section{RESULTADOS E DISCUSSÕES}

Os resultados que serão apresentados nesta seção estão divididos em duas partes. A primeira descreve o perfil dos conselheiros entrevistados, sendo analisado, além de características pessoais, o perfil participativo deles. Já a segunda parte dos resultados refere-se à percepção dos conselheiros em relação ao espaço deliberativo e suas atribuições.

\subsection{Quem Participa?}

O Conselho Municipal de Saúde de Belo Horizonte, assim, como os demais Conselhos de Políticas Públicas não são espaços restritos e fechados aos conselheiros, pelo contrário, toda população tem acesso a ele, menos o direito ao voto. No caso de Belo Horizonte, a participação institucionalizada vai além, a rede conta com a participação de mais de 3.000 pessoas ligadas de alguma forma à gestão do SUS, seja pelo conselho municipal, distrital ou local, seja pelas entidades envolvidas com o Conselho.

Dentre os conselheiros, em relação ao nível de escolaridade, é observado uma tendência escalar, ou seja, os representantes dos usuários entre o ensino fundamental e médio, os trabalhadores com nível superior e os membros da gestão e prestadores com superior completo ou pós-graduação. O nível de escolaridade em uma instituição deliberativa não irá julgar quem ou qual segmento terá superioridade no processo decisório. No entanto o conselheiro deve possuir a capacidade para participar das deliberações, a qual, de acordo com Brugué (2007), deve ser o equilíbrio de falar e escutar, de saber expor suas próprias posições durante o discurso.

No entanto nem todos conselheiros receberam instruções básicas para participar ativamente desse espaço. Seis dos entrevistados alegaram não ter recebido nenhum tipo de informação sobre o que é e como atuar no Conselho. Dos demais, dois afirmaram ter recebido um curso de capacitação no início dos trabalhos, e os oito restantes, após se tornarem conselheiros.

Foi observada também uma renovação no Conselho, já que a maioria dos conselheiros entrevistados começou a atuar como tal a partir de 2010. No entanto essa renovação não reflete mudança de perfil dos conselheiros, que, em sua maioria, se encontram na faixa etária de 50 a 60 anos. Esse aspecto foi muito lembrado pelos conselheiros durante as entrevista, os quais apresentaram a preocupação com a baixa presença de um público mais jovem no Conselho.

Além dos conselheiros, membros externos são fundamentais no processo deliberativo, pois, mesmo sem o direito ao voto, têm a possibilidade de participarem das discussões de forma ativa. Entretanto a presença desses ativistas políticos quase não é notada no $\mathrm{CMS} / \mathrm{BH}$, pelo fato de ser considerada uma participação pequena, segundo os entrevistados. Ainda assim, foi unânime a declaração de que a participação da população é de extrema importância no desenvolvimento das atividades. De acordo com Bohman (2009), a deliberação deve envolver toda a população, no entanto, por não ser possível, apenas os eleitos representantes o fazem como conselheiros. Ainda assim, o Conselho é um espaço aberto para todos, justificando o fato de que quanto mais envolvidos no processo melhor será para a deliberação. No entanto foi observado pelos entrevistados, na metrópole estudada, a falta de conhecimento da população acerca do Conselho.

\subsection{Percepção dos Conselheiros}

\subsubsection{Sobre o Papel do Conselho}

Perguntados sobre o papel exercido pelo Conselho diante da gestão do sistema de saúde, os entrevistados o reconheceram como instituição para exercer o papel fiscalizador, tanto das políticas de saúde, quanto das unidades de atendimento.

Nos depoimentos, foi destacado também o aparato deliberativo do Conselho, no entanto o que pode ser observado pelas entrevistas é a sua baixa capacidade propositiva. Inferiram que existe uma tendência de que as discussões devem tomar como origem propostas externas, ou da Secretaria de Saúde ou de outras fontes, sendo estas direcionadoras as ações do Conselho. Essa percepção fragiliza a atuação do Conselho em vista que, no processo de deliberação descrito por Cohen (2009), a formulação da agenda está comprometida, incapacitando o conselho de discutir temas mais profundos nas plenárias. 
Perguntados sobre o alcance dos objetivos do Conselho, em termos de cumprir com o papel que lhe foi atribuído, observou-se uma assimilação de incompletude dos conselheiros, em grande parte, demonstrando falta de conhecimento ou dificuldades para expor com clareza suas opiniões em plenária. Segundo os entrevistados, parte dos assuntos que são discutidos no conselho é de grande complexidade para muitos dos envolvidos, ilustrando esse fato com a prestação de contas da secretaria. Em se tratando desses assuntos, os próprios conselheiros compreendem que lhes falta capacitação para realizar a sua função.

Além da capacitação do conselheiro, outro aspecto que parece preocupar os entrevistados é o acompanhamento pós-deliberação que dificulta verificar se as deliberações do conselho são incorporadas às decisões políticas. A falta de clareza quanto aos resultados de suas ações se apresenta como aspecto limitante à legitimação do Conselho. Embora se espere que, no espaço deliberativo, deva permanecer uma situação de igualdade em termos políticos, uma participação efetivamente paritária, na qual se possa chegar a decisões utilizando-se da força do argumento, os problemas destacados pelos entrevistados parecem implicar enfraquecimento do intercâmbio de argumento, por falta de informações esclarecedoras e por falta de vinculação das decisões do conselho com as decisões governamentais.

Para os entrevistados, o Conselho tem atuado aquém das suas possibilidades e, mesmo reconhecendo a sua importância no processo de democratização, compreendem que, em se tratando de gestão da saúde em Belo Horizonte, esta fica a cargo da Secretaria Municipal de Saúde e, na prática, não é compartilhada. Para eles, se o Conselho não se manifestar, a secretaria não se esforçará para que isto aconteça.

Em reflexo à percepção dos entrevistados que caracterizaram o Conselho, em grande parte, como órgão fiscalizador e não propositor de novas políticas, observou-se que, para os entrevistados, quando o Conselho procura propor políticas, acaba esbarrando em dificuldades processuais. Em consonância, alguns dos conselheiros afirmaram que propor não é função do conselho, e sim da Secretaria de Saúde, ficando este responsável apenas pela decisão de aceitar ou não as propostas, o que não inviabiliza a inserção da sociedade nas discussões políticas. Segundo Brugué (2009), diferente de uma democracia com base apenas na representação, na administração pública deliberativa, os membros do conselho podem transformar as políticas em que estão envolvidos, permitindo, assim, a inserção de propostas ainda que o processo tenha sido iniciado pelo governo.

Em termos de compartilhamento da gestão da saúde, prevista no aparato legal que institucionaliza os Conselhos no Brasil, buscou-se compreender como se dá a relação de interação do conselho com a administração pública.

De acordo com os entrevistados, em muitas ocasiões, a secretaria de saúde ultrapassa os seus limites na tentativa de promover ações que deviam passar a priori pela plenária do conselho. A resposta de um entrevistado ilustra essa situação: "infelizmente não existe este compartilhamento, eles não procuram fazer (gestores). A gente tem que correr atrás, e você viu, hoje mesmo, que eles querem ultrapassar os nossos limites, mas a gente procura fazer prevalecer os nossos interesses" (ENTREVISTADO 6, 2013). A situação citada pelo entrevistado se referia a uma mudança na estrutura do planejamento da secretaria de saúde que a gestão começou a fazer sem passar pela plenária do conselho.

Outro entrevistado, confirmando essa linha de pensamento, relata sobre a visão que a secretaria parece ter sobre o conselho e a participação. Para ele, a secretaria não entende o direito de participação dos conselheiros nesse espaço, acham que eles "podem" participar e não que são também, membros nas decisões da saúde municipal.

Esse argumento leva o CMS/BH em direção à afirmação de Gohn (2000), a partir da qual:

Apesar da legislação incluir os conselhos como parte do processo de gestão descentralizada e participativa, e constituí-los como novos atores deliberativos e paritários, vários pareceres oficiais têm assinalado e reafirmado o caráter apenas consultivo dos conselhos, restringindo suas ações ao campo da opinião, da consulta e do aconselhamento, sem poder de decisão ou deliberação. (GOHN, 2000 p. 179). 
Se confirmada a baixa autonomia do CMS/BH, o papel e o objetivo deste estará fadado a cumprir um papel de consulta do poder executivo para as decisões que esta tomará centralizada como gestor da saúde. No entanto houve falas dos entrevistados com visões contrárias, ou no sentido da existência de compartilhamento ou na força do CMS/BH diante seus direitos, sendo muito comentado pelos entrevistados o dia em que o Conselho conseguiu exonerar o Secretário Municipal de Saúde que não se adequava à metrópole e sua população. Ainda assim, pode-se afirmar que o CMS/BH está com o sinal amarelo em alerta, no entanto não necessariamente irá para o vermelho.

\subsubsection{Sobre o Funcionamento do Conselho}

O cotidiano do Conselhoé definido por uma série de normas e diretrizes que definem os procedimentos que devem ser executado e como. Desse modo, nesse aspecto, buscou-se identificar como se dá o processo decisório do Conselho, o de fiscalização, de gestão orçamentária e, por último, se os conselheiros reconhecem a igualdade dentre os membros durante a plenária.

Quanto ao processo deliberativo, de acordo com os entrevistados, os assuntos que entraram em pauta, passam primeiro por Câmaras Técnicas (CT's). Estas são espaços dentro do conselho que se aprofundam nos assuntos que entraram em deliberação para subsidiar as plenárias antes das votações. De acordo com Faria (2007), as CT's fornecem condições para tornar os conselheiros mais aptos a discutirem os assuntos que serão colocados em pautas, já que são mais bem informados.

Sobre as pautas do Conselho, é importante destacar a forma como são colocadas em reunião. De acordo com o Regimento do Conselho, a convocação para as reuniões pode ser feita pela Mesa Diretora do CMS/ $\mathrm{BH}$, por $1 / 3$ dos membros do Conselho ou por convocação do Conselho Estadual de Saúde. A Mesa Diretora, além de ter o direito de convocar para as reuniões, é quem organiza as pautas que serão colocadas para deliberação nas plenárias, o que justifica a necessidade de uma Mesa Diretora democrática formada por membros de todos os segmentos, afinal a maior predominância de um segmento sobre outro pode direcionar os assuntos em pauta de acordo com o interesse daqueles representantes.

Em relação ao processo de fiscalização das unidades de saúde, as respostas encontradas vão de acordo com as descritas na seção anterior como o ponto mais forte do CMS/BH de acordo com os conselheiros. Esse processo, segundo os entrevistados, ocorrem para fiscalizar obras, contratos e as unidades de saúde com as visitas técnicas.

A importância das CT's para o CMS/ $\mathrm{BH}$ também foi observado nesse ponto. A CT, por exemplo, fiscaliza todos os recursos que foram comprometidos para obras e custeio da saúde, analisando o que foi destinado e o que está sendo empregado, aumentando assim a accoutability, um dos resultados esperados pela democracia deliberativa (MARQUES, 2009). De acordo com Fung (2004) elevar a accountability é algo possível em espaços deliberativos, já que:

[...] através da deliberação pública
organizada, os cidadãos podem
examinar coletivamente as ações e
políticas dos representantes, avaliar
o alinhamento deste comportamento
do Estado com suas próprias aspi-
rações e valores e tentar colocar os
dois em conformidade. (FUNG, 2004,
p. 187).

Em relação ao orçamento do Fundo de Saúde de Belo Horizonte, foi observada certa confusão entre os entrevistados sobre a forma como ocorre a gestão desse recurso.

De acordo com as competências da Resolução 453 de 2012,

XIV - o conselho de saúde propor cri-
térios para programação e execução
financeira e orçamentária dos Fundos
de Saúde e acompanhar a movimen-
tação e destino dos recursos; XV - fis-
calizar e controlar gastos e deliberar
sobre critérios de movimentação de
recursos de saúde, incluindo o Fundo
de Saúde e os recursos transferidos e
próprios do Município, Estado, Dis-
trito Federal e da União, com base no
que a lei disciplina. (BRASIL, 2012).

Dos conselheiros que participaram da pesquisa, nem todos souberam explicar como se dá a forma de gestão desse recurso, porém 
todos explicaram que, em um primeiro momento, o recurso vai para a CT, que aprecia todos os relatórios emitidos pela secretaria de saúde. Em seguida, após a análise da câmara, um parecer é levado para a plenária do Conselho para que seja deliberado sobre a aprovação, ou não, do relatório.

Nesse panorama, como nos demais, observa-se a necessidade de uma CT forte e de formação democrática, assim como o próprio Conselho. Aqueles conselheiros que responderam não conhecerem ou não terem certeza sobre a gestão orçamentária apontaram as CT's como "responsáveis" pelo controle financeiro, sendo de responsabilidade do Conselho apenas a votação dos pareceres, o que desvia a noção da plenitude atribuída ao CMS, uma vez que o conhecimento de cada membro é fragmentado nas $\mathrm{CT}^{\prime}$ 's e estas direcionam a votação na plenária devido ao conhecimento abstrato do tema dos demais conselheiros.

Procurou-se também constatar a percepção que os conselheiros possuem sobre o equilíbrio da participação nas plenárias do CMS/BH, equilíbrio este embasado na teoria deliberativa, a partir da qual Benhabib (2009) e Cohen (2009) definem como legitima a deliberação em espaços nos quais o poder comunicativo é livre de preconceitos, igualitário e pluralista. As principais contradições entre as respostas encontradas possibilitaram a categorização em três escalas: 1) Aqueles que acham que existe pouco ou nenhum equilíbrio; 2) os que se posicionam de forma intermediária e os que 3) percebem no Conselho o equilíbrio entre os membros.

Em relação aos posicionamentos contrários ao equilíbrio, observou-se um dos fatores e causas do constrangimento da fala durante as plenárias a percepção de conselheiros mostrando-se superiores a outros. No entanto o que se identifica reflete na pluralidade do Conselho, na existência de membros com elevado grau de escolaridade e outros com baixa, na existência de conselheiros que estão estritamente ligados à gestão do SUS e aqueles que são apenas usuários. Essa diferença é a esperada em um espaço deliberativo, pois, em uma arena democrática na qual o discurso prevalece, as diferenças ideológicas de cada segmento devem contribuir para um resultado equilibrado.
De acordo com Gohn (2000), a questão da representatividade constitui problemas cruciais nos conselhos de políticas públicas; já para Nobre (2004), o processo deliberativo é baseado na troca de informações entre diversos grupos, diferentes sindicatos, diferentes instituições.

Nesse espaço, a diferença deve ser respeitada para que aqueles com sentimentos de inferioridade sintam-se motivados a participarem das discussões, afinal a existência desse espaço se dá pela necessidade de que todos os envolvidos com a saúde possam contribuir positivamente com ela. No processo deliberativo, o mais importante é o discurso, a comunicação e que no final todos estejam de acordo com o resultado. Essa ideia vai ao encontro do que afirma Brugué (2009), para quem o diálogo e a comunicação entre os membros é o coração de um processo deliberativo. Para ele, é a construção de um resultado com base na conversação e na troca de razões que legitima esse espaço.

Alguns entrevistados se posicionaram de forma intermediária, ou seja, perceberam a existência de uma igualdade limitada, no entanto com um sentimento de que esta não chega a ser totalmente encontrada devido a situações ligadas à capacitação e na posição de cada segmento dentro do Conselho.

Um entrevistado relatou que o conselho está dividido em duas posições, os que estão a favor da gestão e os contrários à secretaria de saúde. Além disso, os mais presentes no Conselho são os usuários. Essa percepção de presença e/ou ausência de um segmento em relação a outro está profundamente ligada ao perfil dos conselheiros. A atividade exercida por um representante, nesse espaço, não é remunerada e demanda tempo; isto ocorre porque os processos não são iniciados e finalizados durante a plenária; se iniciam, nem se finalizam apenas durante a plenária, o que prejudica a representação de determinados segmentos e transforma o espaço em um ambiente no qual a participação se dá, em maior quantidade, entre aposentados usuários do SUS, frentes e movimentos sindicais.

Por último, alguns conselheiros confirmaram a existência de equilíbrio entre todos os membros e, para fortificarem esse argumento, citaram as resoluções e regimentos do Conselho que garantem a sua 
paridade. Mesmo com o sentimento de um desiquilíbrio no conselho por parte de alguns entrevistados, pode ser observado que estes reconhecem a importância da participação no Conselho e prezam pela busca do equilíbrio entre os representantes.

Além disso, segundo Gutmann e Thompson (2009), o processo democrático deliberativo, a partir da troca de razões, é necessário não apenas para que a decisão seja legítima, mas também justa, ou seja, que todos estejam de acordo com os resultados. Essas ideias dialogam com os estudos de Gugliano (2004, p. 227) que afirma: "[...] o principal ganho com este modelo participativo é a aproximação da democracia da via cotidiana e sua inserção em novos espaços de convivências entre os cidadãos que potencializam a discussão sobre a democratização de esferas extra-estatais".

Assim, a questão da paridade justifica a necessidade de que nenhum segmento seja superior a outro, pelo contrário, esse espaço é para que todos aqueles que queiram participar da gestão da saúde o façam, de forma igualitária e livre, como defende Gugliano (2004).

\section{CONCLUSÃO}

O Conselho Municipal deSaúde de Belo Horizonte possui estrutura e condições necessárias para o exercício de suas atividades; uma sede, com equipamentos e recursos que permitem a execução das atividades e dispõe de normas e diretrizes atualizadas e Câmaras Técnicas ativas para discussão dos variados assuntos sobre a gestão da saúde, cujos pareceres subsidiam as discussões em plenária. No entanto foram identificados alguns desafios que impossibilitam uma dinâmica adequada das atividades do Conselho enquanto espaço democrático.

Embora o CMS/BH seja constituído para exercer diversas competências, tais como a proposição e acompanhamento de políticas públicas, controle orçamentário e fiscalização da gestão e das unidades de saúde, notou-se, a partir do Conselho estudado, a predominância deste último.

A democracia deliberativa tem como principal objetivo permitir a inserção dos cidadãos nas discussões políticas, de maneira que os afetados pelas políticas possam apontar problemas e participar do processo de construção de soluções para estes. Assim, quando a arena participativa, no caso o Conselho Municipal de Saúde de Belo Horizonte, começa apenas a discutir sobre as propostas do poder central, o conselho acaba por se tornar uma instituição consultiva (GOHN, 2000), o que não representa o papel legitimado desse espaço.

Ainda que reconhecida a importância do Conselho enquanto órgão fiscalizador, os depoimentos sinalizaram para o seu enfraquecimento enquanto instituição política, conferindo assim uma submissão à Secretaria Municipal de Saúde de Belo Horizonte.

Constatou-se, a partir das entrevistas, o entendimento dos conselheiros acerca do funcionamento do CMS/BH e o interesse pelas formas e pelos direito de agir, no entanto infere-se que o fazer valer fica restrito apenas à plenária, em vista que o equilíbrio entre os representantes nesse espaço não foi encontrado em plenitude.

Embora seja reconhecido o poder do Conselho e mesmo que este faça uso de artifícios como o Ministério Público para que seu papel seja cumprido, o fundamental para o CMS/BH seria que isto não precisasse ocorrer. Para tal, demanda-se da gestão municipal a admissão desse espaço nas políticas públicas de saúde; um Conselho forte e impositivo sobre o poder executivo e uma sociedade civil participativa expressiva.

Conclui-se, a partir deste estudo, que o Conselho Municipal de Saúde, embora institucionalizado na gestão há mais de duas décadas, ainda busca formas para legitimar suas atividades enquanto espaço democráti$\mathrm{co}$, no entanto o CMS/BH segue adequadamente as regulamentações, reunindo-se com frequência, deliberando assuntos diversos sobre a saúde municipal e buscando, quando preciso, o apoio do Ministério Público.

Como fonte de pesquisa, sugere-se neste trabalho avanços em estudos com as câmaras e comissões internas dos Conselhos municipais, já que nestes espaços é que as discussões são aprofundadas, possibilitando também a ampliação de competências e geração de informação. 


\section{REFERÊNCIAS}

ALENCAR, E. Metodologia de pesquisa social. Lavras, MG: UFLA/FAEPE, 2000.

AVRITZER, L.; PEREIRA, M. L. D. Democracia, participação e instituições híbridas. Revista Teoria e Sociedade, Belo Horizonte, Número Especial, maio 2005.

AVRITZER, L. Sociedade civil e participação no Brasil democrático. In: AVRITZER L. (Org.). Experiências nacionais de participação social. São Paulo: Cortez, 2010.

BENHABIB, S. Rumo a um Modelo Deliberativo de Legitimidade Democrática. In: MARQUES, A. C. S. A deliberação pública e suas dimensões sociais, políticas e comunicativas. Belo Horizonte: Autêntica, 2009. p. 31-84.

BOHMAN, J. O que é a deliberação pública? Uma abordagem dialógica. In: MARQUES, A. C. S. A deliberação pública e suas dimensões sociais, politicas e comunicativas. Belo Horizonte: Autêntica, 2009. p. 31-84.

BRASIL. Lei 8.142 de 28 de dezembro de 1990. Disponível em: <http:/ / portal.saude.gov.br/portal/arquivos/ pdf/Lei8142.pdf.>. Acesso em: 14 jul. 2012.

Resolução n. 333 de 2003. Disponível em: <http://conselho.saude.gov.br/biblioteca/livros/ resolucao_333.pdf.>. Acesso em: 14 jun. 2012.

Resolução n. 453 de 2012. Disponível em: <http:/ / conselho.saude.gov.br>. Acesso em: 14 jun. 2013.

BRESSER-PEREIRA, L. C. Democracia republicana e participativa. Novos estudos CEBRAP, São Paulo, v. 71, p. 77-91, mar. 2005.

A construção política do Estado. Lua Nova, São Paulo, p. 117-146, 2010.

BRUGUÉ, Q. Uma administracion que habla es uma administración qu e piensa: de la gestión pública a la administración deliberativa. In. GOBIERNO DE ARAGÓN. Participación Ciudadana para uma Administracion Deliberativa. [S.1.: s.n.], 2009. p. 55-72

COHEN, J. Deliberação e legitimidade democrática. In: MARQUES, Â. C. S. A deliberação pública e suas dimensões sociais politicas e comunicativas: textos fundamentais. Belo Horizonte: Autêntica, 2009. p. 85-108.

FARIA, C. F. Sobre os Determinantes das Políticas Participativas: a estrutura normativa e o desenho institucional dos Conselhos Municipais de Saúde e de Direitos da Criança e do Adolescente no Nordeste. In: AVRITZER, L. A participação social no Nordeste. Belo Horizonte: Editora UFMG, 2007.

FUNG, A. Receitas para esferas públicas: oito desenhos institucionais e suas consequências. In: COELHO, V.S. P. Participação e deliberação: teoria democrática e expe- riências institucionais no Brasil contemporâneo. São Paulo: Editora 34, 2004.

GODOY, A. S. Estudo de Caso. In: GODOI, C.K.; BANDEIRA-DE-MELO, R.; SILVA, A.B. (Org.). Pesquisa qualitativa em estudos organizacionais: paradigmas, estratégias e métodos. São Paulo: Saraiva, 2006.

GOHN, M. G. O papel dos conselhos gestores na gestão urbana. In: TADEI, A. C. R. E. Repensando a experiência urbana na América Latina: questões, conceitos e valores. Buenos Aires: CLACSO, 2000.

GUGLIANO, A. A. Democracia, participação e deliberação: contribuições ao debate sobre possíveis transformações na esfera democrática. Civitas, Porto Alegre, RS, v. 4, p. 257-283, jul./dez. 2004.

GUTMANN, A.; THOMPSON, D. Democracia deliberativa para além do processo. In: MARQUES, A. C. S. A deliberação pública e suas dimensões sociais políticas e comunicativas: textos fundamentais. Belo Horizonte: Autêntica, 2009. p. 85-108.

HABERMAS, J. Três modelos normativos de democracia. Lua Nova, São Paulo, v. 36, p. 39-53, 1995.

LABRA, M. E. Conselhos de Saúde. Dilemas, avanços e desafios. In: LIMA, N.; GERSCHAMAN, S.; EDLER, F.; SUÁREZ, J. (Org.). Saúde e democracia. História e perspectivas do SUS. 1. ed. Rio de Janeiro: FIOCRUZ, 2005. v. 1, p. 353-383.

MARQUES, A. C. S. As interações entre o processo comunicativo e a deliberação pública. In: MARQUES, A. C. S. A deliberação pública e suas dimensões sociais políticas e comunicativas: textos fundamentais. Belo Horizonte: Autêntica, 2009. p. 85-108.

NEVES, J. L. Pesquisa qualitativa: características, usos e possibilidades. Cadernos de Pesquisas em Administração, v. 1, n. 3, 2 sem. 1996.

NOBRE, M. Participação e deliberação na teoria democrática: uma introdução. In: COELHO, V. S. P. Participação e deliberação: teoria democrática e experiências institucionais no Brasil contemporâneo. São Paulo: Editora 34, 2004.

PAULA, A. P. P. de. Por uma nova gestão pública: limites e potencialidades da experiência contemporânea. Rio de Janeiro: FGV, 2005.

SPINK, P. Redução da pobreza e dinâmica locais. Rio de Janeiro: FGV, 1998.

UGARTE, P.S. Que participação para qual Democracia. In: COELHO, V. S. P. Participação e deliberação: teoria democrática e experiências institucionais no Brasil Contemporâneo. São Paulo: Editora 34, 2004. 